\title{
OPTIMIZATION STUDY OF DYE REMOVAL BY CEMENT KILN DUST USING THE CENTRAL COMPOSITE DESIGN OF EXPERIMENTS
}

\section{ÇORUH S. ${ }^{1}$} ELEVLI S. ${ }^{2}$

\author{
${ }^{a}$ Department of Environmental Engineering \\ Ondokuz Mayis University, 55139 Samsun, Turkey \\ ${ }^{b}$ Department of Industrial Engineering \\ Ondokuz Mayis University, 55139 Samsun, Turkey
}

Received: 05/05/201

Accepted: 30/06/2014

Available online: $26 / 11 / 2014$ *to whom all correspondence should be addressed: e-mail: semcoruh@omu.edu.tr

\begin{abstract}
Designed experiments are used to systematically examine the relationship between response variable and a set of experimental factors. In this study, $2^{3}$ factorial design with center points was used to verify the selected experimental factors influence the removal efficiency and linearity assumption is not valid. Optimization experiments were then done to determine the best settings of the experimental factors and define the nature of curvature. Central Composite Design was used to fit a second-degree model since it was possible to build the previous $2^{3}$ factorial design up into a central composite design by adding axial points. According to optimization results, the removal efficiency is maximized when concentration:110 $\mathrm{mg} \mathrm{l}^{-1}$, dosage: $22 \mathrm{~g} \mathrm{l}^{-1}$ and reaction time: $123 \mathrm{~min}$. The predicted yield at these settings is $99.4623 \%$.
\end{abstract}

Keywords: Malachite green, adsorption, cement kiln dust, central composite design

\section{Introduction}

Dyes are widely used in industries such as textile, rubber, paper, plastic, cosmetic, etc. leather dyeing, color photography and as additives in petroleum products (Demirbas and Nas, 2009; Dawood, 2010). Some of the dyes are carcinogenic and mutagenic because they were formerly made by hazardous chemicals such as benzidine, metals, etc. The discharge of colored wastes into the receiving water bodies not only affects their aesthetic nature but also interferes with the transmission of sunlight and therefore reduces the photosynthetic activity (Lin et al., 2008; Rastogi et al., 2008, Fernandes et al., 2007). Malachite green (MG) is one such dye which is used as a food coloring agent, as a medical disinfectant and in dyeing in silks, cooton, wool, paper, jute and leather industries. MG is a carcinogen and mutagen, causing chromosomal fractures in rainbow trout. MG also acts as a respiratory enzyme poison and causes respiratory distress in rainbow trout. Therefore, the removal of MG from wastewater before discharging to the environment is necessary and very important (Ahmad and Alrozi, 2011; Baek et al., 2010; Mittal, 2006; Rajgopal et al., 2006).

Recently, some researchers reviewed a wide variety of low-cost adsorbents for the removal of heavy metals and dyes (Gupta and Suhas, 2009; Kyzas, 2012; Kyzas et al., 2012). Activated carbon is the most popular adsorbent, which is capable of adsorbing many dyes with a high adsorption capacity. But it is expensive and the costs of regeneration are high because desorption of the dye molecules is not easily achieved. Recently, the sorption properties of various low cost industrial by-products or natural materials have been investigated intensively for immobilization of heavy metal ions from wastewater. It is important to note that the metal sorption capacity of low cost adsorbents depends on the material 
characteristics, surface modification and the initial concentration. In overall, the technical applicability and cost effectiveness are two key factors in the selection of suitable adsorbent for treating inorganic effluents (Bukallah et al., 2007; Mahmoued, 2010; Salem et al., 2012).

Cement kiln dust (CKD) is one of such industrial waste or by product which is progressively significant environmental concern related to its emission and disposal. In the manufacturing Portland cement, cement industries generate millions of tons of cement cement kiln dust. CKD is a particulate matter that is collected from electrostatic precipitators during the production of cement clinker and consists of entrained particles of clinker, unreacted and partially calcined raw materials, and fuel ash enriched with alkali sulfates, halides, and other volatiles. Analysis of cement kiln dust with X-ray diffraction studies revealed that limestone $\left(\mathrm{CaCO}_{3}\right)$ is the major component of CKD whereas, quartz (SiO4) together with small quantity of gypsum $\left(\mathrm{CaSO}_{4}\right)$, sodium chloride $(\mathrm{NaCl})$, arcanite $\left(\mathrm{K}_{2} \mathrm{SO} 4\right)$, spurite $\left[2\left(\mathrm{C}_{2} \mathrm{~S}\right) \cdot \mathrm{CaCO}_{3}\right]$ and sulfospurite $\left[2\left(\mathrm{C}_{2} \mathrm{~S}\right) \cdot \mathrm{CaSO}_{4}\right]$ constitutes the minor component.Cement kiln dust so generated is partly reused in cement plants and landfilled. Due to lack of landfilling space and ever increasing disposal cost, utilization of CKD in highway uses, waste treatment, soil stabilization, cement mortar/concrete, CLSM, etc. has become an attractive alternative to its disposal. Researchers have investigated the reuse of CKD in a number of fields (e.g. as a soil fertilizer, as a stabilizer of waste water streams, as a partial replacement of soda in glass production, as an anti-stripping agent in asphalts, as components of blended cements and masonry products, etc.,) (Sreekrishnavilasam et al., 2007; Kunal et al., 2012; Salem et al., 2012). Recently, CKD has been reported as a potentially important sorbent due to the high specific surface area, high amount of alkali oxides, excellent thermal resistance. It was indicated that CKD can effectively remove heavy metal and dye ions from wastewater (Salem and Velayi, 2012; Salem et al., 2012).

Response surface methods are used to examine the relationship between one or more response (dependent) variables and a set of quantitative experimental (independent) variables or factors. These methods are often employed to find the factor settings that optimize the response after identifying a "vital few" controllable factors. Designs of this type are usually chosen when curvature in the response surface is suspected by factorial experimental design.

In this study, the effect of experimental factors which are initial dye concentration, adsorbent dosage and reaction time on dye removal efficiency was investigated. Firstly, $2^{3}$ factorial design was used to verify whether or not the selected factors are statistically significant on removal efficiency and the linearity assumption is violated. Central Composite Design has been then used for the purpose of finding optimal settings of these experimental parameters because these designs can incorporate information from twolevel factorial experiments. The experimental data was processed using Minitab 16 Statistical Software.

\section{Experimental procedure}

\subsection{Materials and methods}

The cement kiln dust used in this investigation was from Bartın Cement Company located in North West of Turkey. The used CKD was dried in an electrical laboratory oven at $100^{\circ} \mathrm{C}$. The chemical analysis of CKD is reported in Table 1. The main constituting phases are: calcite $\left(\mathrm{CaCO}_{3}\right)$, quartz $\left(\mathrm{SiO}_{2}\right)$, clinker phases and anhydrite $\left(\mathrm{CaSO}_{4}\right)$. The specific surface area (BET, Quantachrome Instruments, Nova 2200e) of cemeny kiln dust is around $4.2 \mathrm{~m}^{2} \mathrm{~g}^{-1}$. The chemical composition of the cement kiln dust was evaluated by using XRay Fluorescence techniques (Spectro-Xepos). The composition of the cement kiln dust is presented in Table 1. The morphology of particles in the used powders was examined with a scanning electron microscopy test (SEM, Zeiss Supra 5OVP), operating at $30 \mathrm{kV}$ (Fig. 1).

The basic dye, malachite green $\left(\mathrm{C}_{23} \mathrm{H}_{26} \mathrm{CIN}_{2}\right)$, was selected for adsorption studies. The stock solution of $1000 \mathrm{mg} \mathrm{l}^{-1}$ was prepared by dissolving accurately weighed amounts of malachite green in $1000 \mathrm{ml}$ distilled water. Table 2 shows some properties of malachite green dye. Adsorption properties of cement kiln dust were evaluated by depending on different adsorption conditions such as different initial dye concentrations, contact times and adsorbent dosage. Dye concentration was measured using a UV-Vis 
Spectrophotometer (Hettich Universal 320) at $\lambda \max$ of $620 \mathrm{~nm}$. The dye solution $(100 \mathrm{~mL})$ at desired concentration ( 49 and $161 \mathrm{mg} \mathrm{l}^{-1}$ ), adsorbent dosage ( 6.9 and $24 \mathrm{~g} \mathrm{l}^{-1}$ ) and contact time (40 and 145min) taken in $250 \mathrm{~mL}$ Erlanmayer flasks was used. The flasks were kept under agitation in a rotating shaker (Julabo SW22) at $150 \mathrm{rpm}$ until equilibrium was reached. The dye solution was centrifuged at 3000rpm for separation of cement kiln dust from aqueous solution. All experiments were conducted in duplicate and the average values were used for data analysis.

Table 1. Chemical composition (wt. \%) of cement kiln dust

\begin{tabular}{cc}
\hline & Cement kiln dust \\
\hline $\mathrm{SiO}_{2}$ & 0.20 \\
\hline $\mathrm{Fe}_{2} \mathrm{O}_{3}$ & 0.90 \\
\hline $\mathrm{Al}_{2} \mathrm{O}_{3}$ & 0.80 \\
\hline $\mathrm{CaO}$ & 55.30 \\
\hline $\mathrm{K}_{2} \mathrm{O}$ & 0.93 \\
\hline $\mathrm{MgO}$ & 0.50 \\
\hline $\mathrm{Na}_{2} \mathrm{O}$ & 0.85 \\
\hline $\mathrm{MnO}$ & 0.75 \\
\hline $\mathrm{TiO}_{2}$ & 0.68 \\
\hline $\mathrm{LOI}^{*}$ & 39.09 \\
\hline
\end{tabular}

*Loss on ignition

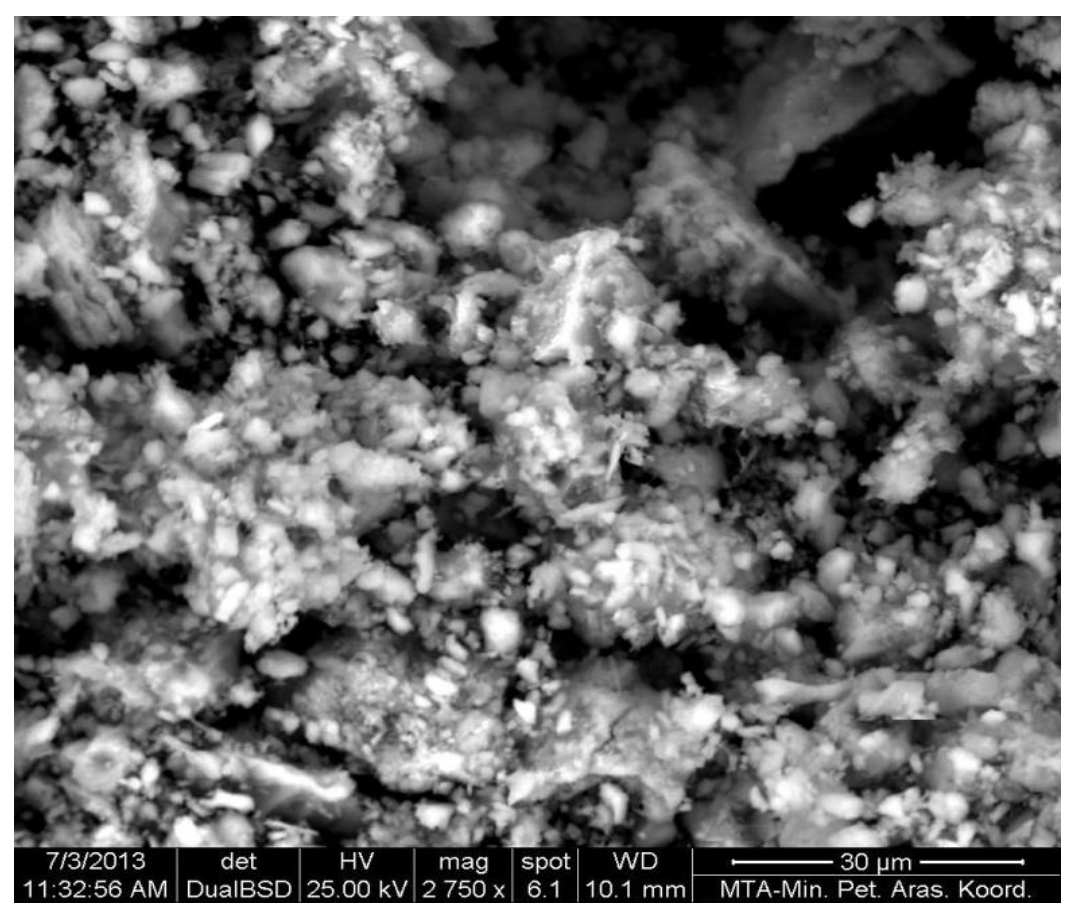

Figure 1. SEM spectrum of cement kiln dust

The removal efficiency $(E)$ of the cement kiln dust on malachite green dye was calculated according to the following formula (Eq. 1):

$E(\%)=\frac{C_{0}-C}{C_{0}} \times 100$ 
where $\mathrm{Co}$ is the initial concentration of the dye solution and $\mathrm{C}$ is the final concentration of the dye solution.

Table 2. Some properties of malachite green dye

\begin{tabular}{cc}
\hline Basic Dyes Properties & Malachite green \\
C.I. No & 42000 \\
CAS No & $5596-64-2$ \\
Molecular Weight \\
Melting Point \\
C.I. Name
\end{tabular}

\subsection{Central Composite Design}

Response surface methodology (RSM) is used to model the relationship between the quantitative factors and the response and to find factor settings that produce the "best" response. These designs are capable of fitting a second order prediction equation for the response as follows:

$y=\beta_{0}+\sum_{i=1}^{k} \beta_{i} x_{i}+\sum_{i=1}^{k} \sum_{j>i}^{k} \beta_{i j} x_{i} x_{j}+\sum_{i=1}^{k} \beta_{i i} x_{i}^{2}+\varepsilon$

There are many cases where the linear model (first order prediction model) is not sufficient to represent the experimental data adequately. In this case, response surface methods are used to determine a quadratic response surface which has curvature and to predict factor levels that produce maximum or minimum response values (Tarley et al, 2009). Central composite design (CDD), one of the most known RSM methods, is especially useful in sequential experiments because it is built on previous factorial experiments by adding axial and center points.

Central composite designs consist of cube points, center points and axial points. A factorial or fractional factorial design ( $2^{\mathrm{k}}$ or $2^{\mathrm{k}-1}$ factorial points, where $\mathrm{k}$ is the number of factors) allow for the estimation of linear and interaction effects. Center points are used to check for curvature (Montgomery, 2013). Finally, axial (or star) points are used to estimate quadratic terms. Alpha $(\alpha)$ for axial points is the distance of each axial point from the center and calculated by $\alpha=2^{k / 4}$.

\section{Results and Discussion}

Experimental design studies usually starts with screening experiments such as $2^{k}$ factorial designs to select the significant experimental factors and to identify whether or not linearity assumption is violated, and then continues with an experimental optimization design, such as Central Composite Design.

In this study $2^{3}$ factorial design was used to check if the selected experimental factors are significant on dye adsorption process and there is curvature before optimization study. In order to check whether or not the linearity of the effects is a reasonable assumption, center points were added to the factorial design (Table 3). 
Table 3. Experimental Data Set and Design Matrix for Two-Level Factorial Design

\begin{tabular}{|c|c|c|c|c|}
\hline Factors & Symbols & Low level $(-1)$ & Center level (0) & High level $(+1)$ \\
\hline Concentrat & ion $\left(\mathrm{mg} \mathrm{l}^{-1}\right)$ & 49 & 105 & 161 \\
\hline Dosage (g I & $X_{2}$ & 6.9 & 15.45 & 24 \\
\hline Time (min. & $X_{3}$ & 40 & 92.5 & 145 \\
\hline Run No & Concentration $\left(\mathrm{mg} \mathrm{l}^{-1}\right)$ & Dosage $\left(\mathrm{g} \mathrm{l}^{-1}\right)$ & Time (min.) & Removal (\%) \\
\hline 1 & $49(-1)$ & $6.9(-1)$ & $40(-1)$ & 99.42 \\
\hline 2 & $161(+1)$ & $6.9(-1)$ & $40(-1)$ & 6.80 \\
\hline 3 & $49(-1)$ & $24(+1)$ & $40(-1)$ & 99.79 \\
\hline 4 & $161(+1)$ & $24(+1)$ & $40(-1)$ & 65.82 \\
\hline 5 & $49(-1)$ & $6.9(-1)$ & $145(+1)$ & 99.34 \\
\hline 6 & $161(+1)$ & $6.9(-1)$ & $145(+1)$ & 28.57 \\
\hline 7 & $49(-1)$ & $24(+1)$ & $145(+1)$ & 99.67 \\
\hline 8 & $161(+1)$ & $24(+1)$ & $145(+1)$ & 75.15 \\
\hline 9 & $105(0)$ & $15.45(0)$ & $92.5(0)$ & 95.14 \\
\hline 10 & $105(0)$ & $15.45(0)$ & $92.5(0)$ & 94.19 \\
\hline 11 & $105(0)$ & $15.45(0)$ & $92.5(0)$ & 95.42 \\
\hline
\end{tabular}

The null hypothesis stating that the main effects, interactions, and the curvature equal to zero was tested by using F-test (Table 4$)$. The small $P$-values $(<0.05)$ mean that all the main effects and interactions are statistically significant at the $5 \%$ level. $P$-value of curvature term also indicates that there is statistical evidence of curvature so the assumption of linear effects is not reasonable anymore.

Table 4. Analysis of Variance Results for Two-Level Factorial Design

\begin{tabular}{ccccccc}
\hline Source & DF & Seq SS & Adj SS & Adj MS & F & P \\
\hline Main Effects & 3 & 7685.7 & 7685.65 & 2561.88 & 6163.81 & 0.000 \\
\hline Concentration & 1 & 6513.8 & 6153.84 & 6153.84 & 14805.94 & 0.000 \\
\hline Dosage & 1 & 1412.5 & 1412.46 & 1412.46 & 3398.33 & 0.000 \\
\hline Time & 1 & 119.4 & 119.35 & 119.35 & 287.16 & 0.003 \\
\hline 2-Way Interactions & 3 & 1517.4 & 1517.43 & 505.81 & 1216.96 & 0.001 \\
\hline Concentration* dosage & 1 & 1375.5 & 1375.50 & 1375.50 & 3309.41 & 0.000 \\
\hline Concentration*Time & 1 & 122.5 & 122.46 & 122.46 & 294.64 & 0.003 \\
\hline Dosage*Time & 1 & 19.5 & 19.47 & 19.47 & 46.84 & 0.021 \\
\hline 3-Way Interactions & 1 & 19.2 & 19.22 & 19.22 & 46.24 & \\
\hline Concentration*Dosage*Time & 1 & 19.2 & 19.22 & 19.22 & 46.24 & \\
\hline Curvature & 1 & 1163.9 & 1163.90 & 1163.90 & 2800.31 & \\
\hline Residual Error & 2 & 0.8 & 0.83 & 0.42 & & \\
\hline Pure Error & 2 & 0.8 & 0.83 & 0.42 & & \\
\hline Total & 10 & 10387.0 & & & &
\end{tabular}

The factorial and center points in $2^{3}$ factorial design served as a preliminary stage of optimization study by indicating the experimental factors and curvature are statistically significant. In order to include second-order terms to prediction model, $2^{3}$ factorial design in Table 3 was augmented with axial runs to create a central composite design (Table 5).

Analysis of Variance table indicates the significant linear, squared and interaction effects. In order to determine which of the linear, squared and interaction effects in the model are statistically significant, $p$ values were used (Table 6). The $p$-values less than 0.05 mean that there are significant linear effects for all the experimental factors (concentration, dosage and time) and quadratic effects for dosage and time. 
Table 5. Experimental Data Set and Design Matrix for CDD

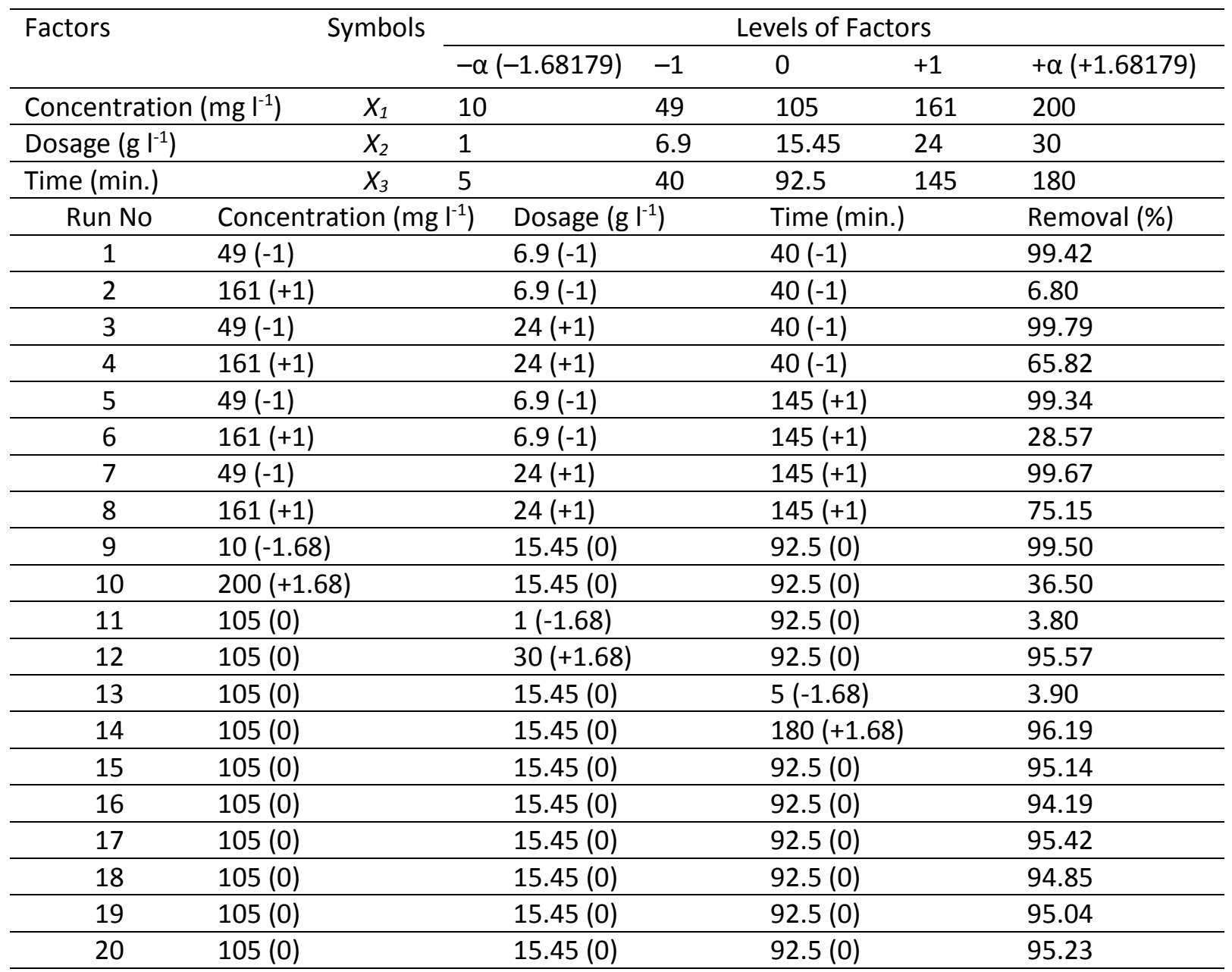

Runs: 20; Cube Points: 8; Center Points in Cube: 6; Axial Points: 6

Table 6. Anova Results for CDD

\begin{tabular}{|c|c|c|c|c|c|c|}
\hline Source & DF & Seq SS & Adj SS & Adj MS & $\mathbf{F}$ & $\mathbf{P}$ \\
\hline Regression & 9 & 20911.1 & 20911.1 & 2323.45 & 6.04 & 0.005 \\
\hline Linear & 3 & 15380.2 & 15380.2 & 5126.72 & 13.33 & 0.001 \\
\hline Concentration & 1 & 7869.6 & 7869.6 & 7869.63 & 20.46 & 0.001 \\
\hline Dosage & 1 & 4974.2 & 4974.2 & 4974.22 & 12.93 & 0.005 \\
\hline Time & 1 & 2536.3 & 2536.3 & 2536.30 & 6.59 & 0.028 \\
\hline Square & 3 & 4013.5 & 4013.5 & 1337.83 & 3.48 & 0.058 \\
\hline $\begin{array}{l}\text { Concentration* } \\
\text { Concentration }\end{array}$ & 1 & 179.4 & 465.1 & 465.07 & 1.21 & 0.297 \\
\hline Dosage*Dosage & 1 & 1748.9 & 2129.6 & 2129.57 & 5.54 & 0.040 \\
\hline Time*Time & 1 & 2085.2 & 2085.2 & 2085.21 & 5.42 & 0.042 \\
\hline Interaction & 3 & 1517.4 & 1517.43 & 505.81 & 1.31 & 0.323 \\
\hline $\begin{array}{l}\text { Concentration* } \\
\text { dosage }\end{array}$ & 1 & 1375.5 & 1375.50 & 1375.50 & 3.58 & 0.088 \\
\hline Concentration* time & 1 & 122.5 & 122.46 & 122.46 & 0.32 & 0.585 \\
\hline Dosage*Time & 1 & 19.5 & 19.47 & 19.47 & 0.05 & 0.827 \\
\hline Residual Error & 10 & 3846.9 & 3846.9 & 384.69 & & \\
\hline Lack of fit & 5 & 3846.0 & 3846.0 & 769.20 & 4152.08 & 0.000 \\
\hline Pure error & 5 & 0.9 & 0.9 & 0.19 & & \\
\hline Total & 19 & 24758.0 & & & & \\
\hline
\end{tabular}


After identifying significant main and squared effects, related statistics were then recalculated by neglecting the terms that seemed statistically insignificant. Table 5 shows the ANOVA results and estimated coefficients of the reduced model to evaluate the included effects. $R^{2}$ value, calculated using the sums of squares in ANOVA table, shows how much of the response variable is explained by terms in the model. According to the analysis results, approximately $68.05 \%$ of variability in removal efficiency is explained by the linear effects of concentration, dosage and time and squared effects of dosage and time.

Table 7. Anova Results and Estimated Coefficients of the Model for CDD (Reduced Model)

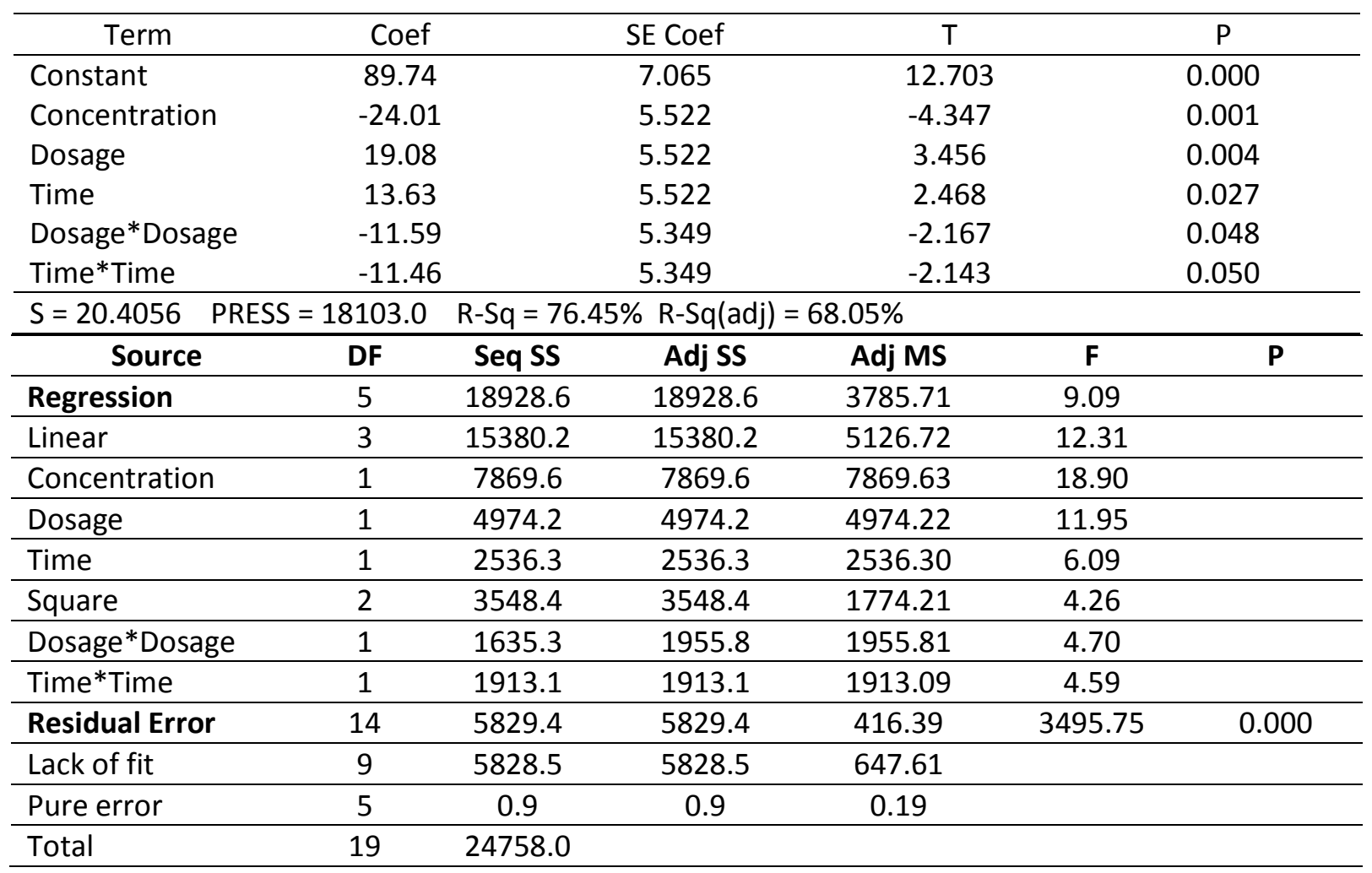

Experimental Design procedures assume that the residual data of model follow a normal distribution. In order to verify this assumption, normal probability plot in Fig. 2 was used. Since the points hugh the fitted line, the null hypothesis $\left(\mathrm{H}_{0}\right)$ that the residual data follow normal distribution cannot be rejected at the $5 \%$ significance level.

Table 7 showed that dosage and time have quadratic effects on removal efficiency, while concentration only has a linear effect. Second-order model based on the estimated coefficients for the parameters is given in Eq. 3. This model can be used as the final model to conduct optimization. It is possible to calculate the optimum points for experimental factors having second-order term through the first derivate of the mathematical function, which describes the response surface and equates it to zero

$\hat{y}=89.74-24.01 \cdot X_{1}+19.08 \cdot X_{2}+13.63 \cdot X_{3}-11.59 \cdot X_{2}^{2}-11.46 \cdot X_{3}^{2}$

Response optimizer in Fig. 3 provides an optimal solution for the experimental factor settings. The removal efficiency is maximized when concentration, dosage and time are set as $110 \mathrm{mg} \mathrm{l}^{-1}, 22 \mathrm{~g} \mathrm{l}^{-1}$ and 123 minutes respectively. Removal efficiency has a high desirability score of 0.89247 because the predicted response of $99.5 \%$ is very close to the target of $100 \%$. 


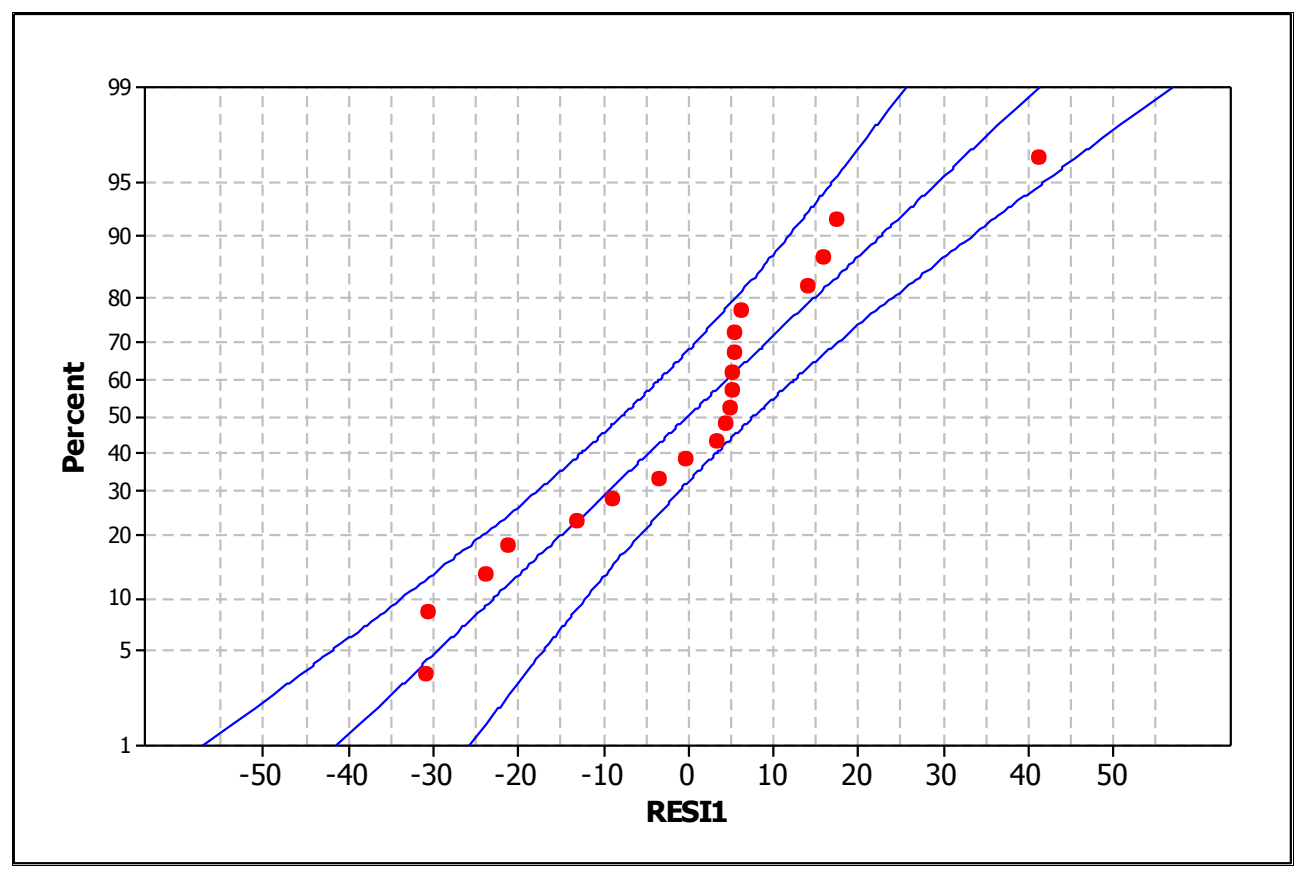

Figure 2. Normal Probability Plot of Residuals

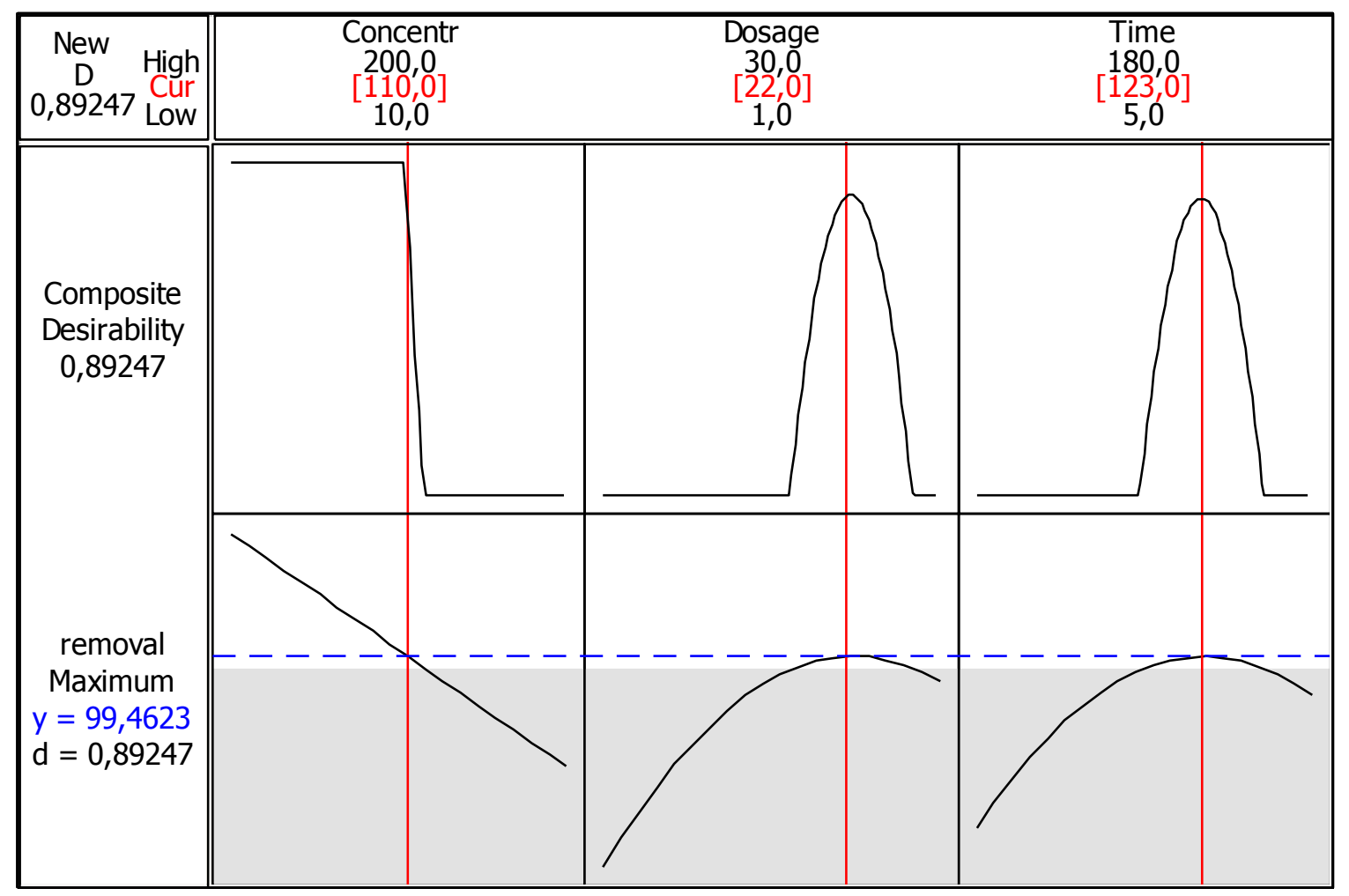

Figure 3. Optimization Plot

Contour plots in Fig.4 show how removal efficiency relates to two experimental factors based on the model given in Eq. (2). Because a contour plot is two-dimensional plot showing only two factors at a time, any other factor was held at an optimized level obtained from optimization plot. These plots are thus only valid for fixed levels of the other experimental factors. 

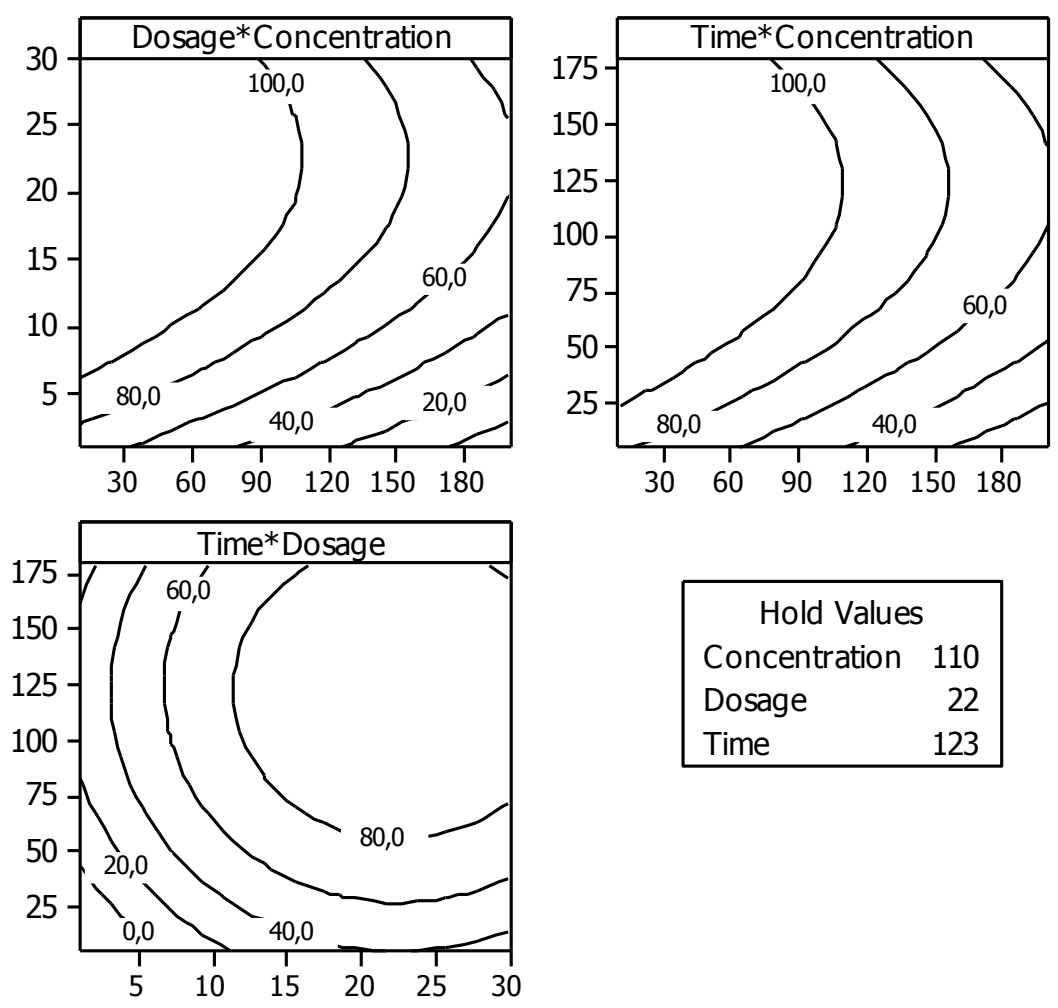

\begin{tabular}{|lr}
\hline \multicolumn{2}{c}{ Hold Values } \\
Concentration & 110 \\
Dosage & 22 \\
Time & 123 \\
\hline
\end{tabular}

Figure 4. Contour Plots

\section{Conclusions}

In this study, response surface design approach using Central Composite Design was applied to develop mathematical model and optimize process parameters for the malachite green dye removal using cement kiln dust. Central composite designs are often recommended when the design plan calls for sequential experimentation because these designs can incorporate information from a properly planned factorial experiment. The factorial and center points may serve as a preliminary stage where you can fit a firstorder (linear) model, but still provide evidence regarding the importance of a second-order contribution or curvature. The optimum values of the initial dye concentration, adsorbent dosage and reaction time were $110 \mathrm{mg} \mathrm{l}^{-1}, 22 \mathrm{~g} \mathrm{l}^{-1}$ and $123 \mathrm{~min}$, respectively. At these conditions, removal efficiency has a high desirability score of 0.89247 because the predicted response of $99.4623 \%$ is very close to the target of $100 \%$. Cement kiln dust showed a good potential for malachite green dye removal and its application is economical than commercial materials.

\section{References}

Ahmad M.A. and Alrozi R. (2011), Removal of malachite green dye from aqueous solution using rambutanpeel-based activated carbon: Equilibrium, kinetic and thermodynamic studies, Chem. Eng. J., 171, 510- 516.

Baek M.H., ljagbemi C.O. and Kim D.S. (2010), Removal of Malachite Green from aqueous solution using degreased coffee bean, J. Hazard. Mater., 176, 820-828.

Bukallah S.B., Rauf M.A., Al Ali S.S. (2007), Removal of Malachite green from aqueous solution by adsorption on sand, Dyes Pigment, 74, 85-87.

Dawood S.G. (2010), Removal Orange (G) Dye from aqueous solution by adsorption on Bentonite, Tikrit J. Pure Sci., 15(1), 231-234. 
Demirbas E. and Nas M.Z. (2009), Batch kinetic and equilibrium studies of adsorption of Reactive Blue 21 by fly ash and sepiolite, Desalination, 243, 8-21.

Fernandes A.N., Almedia C.A.P., Menezes C.T.B., Debacher N.A. and Sierra M.M.D. (2007), Removal of methylene blue from aqueous solution by peat, J. Hazard. Mater., 144, 412-419.

Gupta V.K. and Suhas (2009), Application of low-cost adsorbent for dye removal- A review, J. Environ. Manage., 90, 2313-2343.

Kunal, Siddique R. and Rajora A. (2012), Use of cement kiln dust in cement concrete and its leachate characteristics, Resource Conservation and Recycling, 61, 59-68.

Kyzas G.Z. (2012), A Decolorization Technique with Spent “Greek Coffee" Grounds as Zero-Cost Adsorbents for Industrial Textile Wastewaters, Materials, 5, 2069-2087.

Kyzas G.Z., Lazaridis N.K. and Mitropoulos A.C. (2012), Removal of dyes from aqueous solutions with untreated coffee residues as potential low-cost adsorbents: Equilibrium, reuse and thermodynamic approach, Chem. Eng. J., 189-190, 148-159.

Lin J.X., Zhan S.L., Fang M.H., Qian X.Q. and Yang H. (2008), Adsorption of basic dye from aqueous solution on fly ash, J. Environ. Manage., 87, 193-200.

Mahmoued E.K. (2010), Cement kiln dust and coal filters treatment of textile industrial effluents, Desalination, 255, 175-178.

Mittal A. (2006), Adsorption kinetics of removal of a toxic dye, Malachite Green, from wastewater by using hen feathers, J. Hazard. Mater., B133, 196-202.

Montgomery D.C. (2013), Design and Analysis of Experiments, Eighth Edition, John Wiley \& Sons, Inc.

Rajgopal S., Karthikeyan T., Prakash Kumar B.G. and Miranda L.R. (2006), Utilization of fluidized bed reactor for the production of adsorbents in removal of malachite green, Chemical Eng. J., 116, 211-217.

Rastogi K., Sahu J.N., Meikap B.C. and Biswas M.N. (2008), Removal of methylene blue from wastewater using fly ash as an adsorbent by hydrocyclone, J. Hazard. Mater., 158, 531-540.

Salem A. and Velayi E. (2012), Application of hydroxyapatite and cement kiln dust mixture in adsorption of lead ions from aqueous solution, J. Indust. Eng. Chem., 18, 1216-1222.

Salem A., Afshin H. and Behsaz H. (2012), Removal of lead by using Raschig rings manufactured with mixture of cement kiln dust, zeolite and bentonite, J. Hazard. Mater., 223- 224, 13- 23.

Sreekrishnavilasam A., Rahardja S., Kmetz R. and Santagata M. (2007), Soil treatment using fresh and landfilled cement kiln dust, Constr.Build. Mater., 21, 318-327.

Tarley C.R.T., Silveira G., Santos W.N.L., Matos G.D., Silva E.G.P., Bezerra M.A., Miró M. and Ferreira S.L.C. (2009), Chemometric tools in electroanalytical chemistry: Methods for optimization based on factorial design and response surface methodology, Microchemica. J., 92, 58-67. 